\title{
Wireless Micro-payment System in Networks
}

\author{
Jari Karvonen ${ }^{1)}$ and Petri Pulli ${ }^{2)}$ \\ ${ }^{1)}$ University of Oulu Department of Economic, P.O.Box 4600, FIN-90014 Oulu, Finland, e-mail: \\ Jari.T.Karvonen@oulu.fi, ${ }^{2)}$ University of Oulu Dept of Information Processing \& Infotech \\ Research Center, P.O. Box 1100, FIN-90571 Oulu, Finland, e-mail: Petri.PulIi@oulu,fi
}

Key words: e-cash, mobile payments, ticket

Abstract: Wireless Strategic Initiative (WSI) has recognised the need to develop a PanEuropean wireless micro-payment system framework. ${ }^{4}$ To support this initiative, in this paper the core requirements and desirable characteristics of a simple wireless micro-payment scheme are analysed. The positioning the micro-payment system among the existing monetary vehicles has been considered. The analysis outcome and cornerstone of the proposed approach is to identify the service and let the money be anonymous. Modelling of the micro-payment system has been started using object oriented UML specification language. In this paper partial early models are presented on charging objects (tickets) and associated processing steps (methods). An example service of on-demand MP3 audio stream payment transaction has been elaborated.

\section{INTRODUCTION}

Electric commerce and content services has taken large role on mobile phones. The number of mobile phone's value-added services has increase on recent years. Few years ago the use of mobile phone was mainly speaking. Today the usability of mobile phone has contained many value-added services. Weather, news, real time stock information with buying 
possibilities, automatic machines, parking fee payments etc. have reached daily used position. Market members -new and traditional one- have added wireless dimension on their business models. Mobile phone's use and usability value has increase. World has came more and more wireless and networked. ${ }^{6,7}$ Value increase, the context creation for mobile phones, develops fast. Only one year time on 1998 the development of send short messages sextuple in Finland. ${ }^{5}$ Content will get more educated forms and possibilities to larger the network of offered services. Handsets will develop. Forms of personal data assistants (PDA) are coming on mobile phone area. Laptops will get more educated roots to mobile markets. Japan's I-mode has made familiar to as the laudable applets and educated handsets. Charging base from nowadays minute-tax or use number measures may vary to the number of transferred data. Services have also package and charged by monthly fee like NTT DoCoMo made in Japan. ${ }^{11}$ Income distribution has become more complicated. Copyright fees, many subcontractors and application service providers etc belongs to incoming money distribution root. ${ }^{3}$ Fast and strong development on market intensity requires quite much capacity to satisfy all those needs coming from markets. One bottle- neck has been small money transactions. ${ }^{4}$ This paper show's one needed dimension for futures markets -micro payment system. 


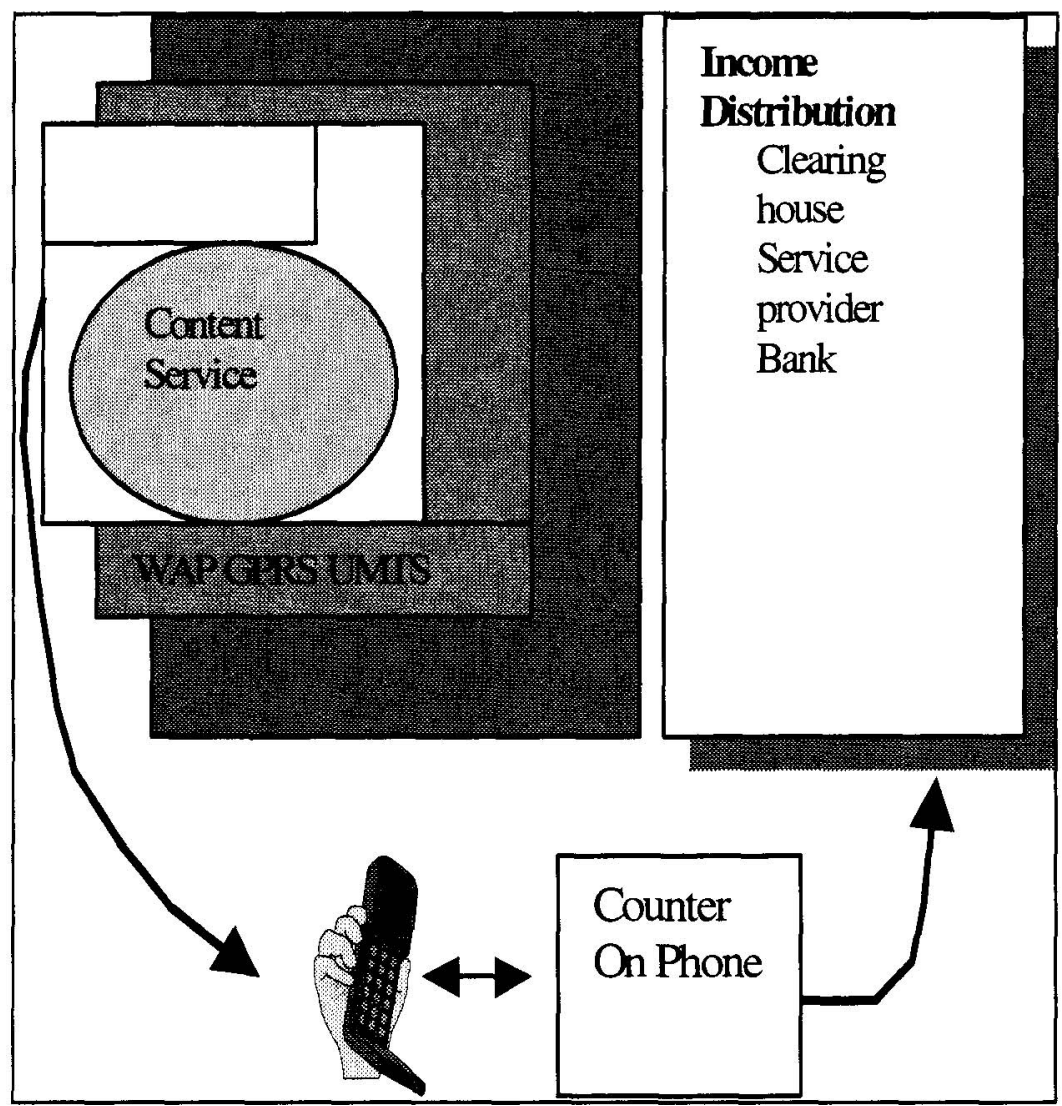

Figure 1. Content, networks and earning distribution

Current payment system in Europe on mobile phones has operator led. Operators collect money from customers. Operators also share the incoming money for value chains other members. Present system has very good advantages. Operator led payment system has clear and well-defined earning logic. Internet has never reach this situation. Operators have a good information from customers. Where they live, what their age is, how they paid their bills, what kind of buying behaviour they have etc are arguments to be found from operator's database. These are clear strengths for the system. Weakness will arise on future, when the use value and the usability of mobile phone arise together with the space of existing services. Change on the market usability of mobile phone in a wider area should influence on the phone bill. Raising bills has limits. Family budget may become more emphasised on mobile phone bill. This might influence on the use of mobile phone. If families find out the high level of mobile phone bill, will they probably cut down the usage! The base for payment may come totally 
elsewhere, like from car wash or parking fee, but the bill's final result is in the form of mobile phone bill. On these support services the role of mobile phone is more like the transaction tool for payments. Consumption should be emphasised straightforward on consumed good.

Wireless digital business is expanding. Mobile phone with traditional GSM network is one channel to this market. WAP brought the access on wireless Internet. GPRS make the access continuous. On future we will get many more mobile networks to satisfy all needs coming from markets. From these the UMTS is probably the most expected. We will get the bluetooth system for tiding our separate equipment together. Substitutive technologies are also coming. W-LAN, wireless local area network, comes to the markets and with broader lane in data transactions than UMTS has. On fixed lines side there is development happening on Internet protocols and on the form of digital TV. The space to make products, services and software enlarges. ${ }^{3,13}$

Handsets, the tools of customer, are also developing. The development may be seen on the need to change the mobile phone. Few years old mobile phone is unusable on the service use. No capability to load ringing tones or logos. Data transaction capability is improve in the newest models. On Japan the phones already include colour screen and still pictures sending possibility. Jawa capable phones are introduced. On the markets there is also powerful mobile equipment. Nokia has had 9000 series Communicator on markets many years. Ericsson made R 380 for similar markets. Both are more like personal data assistants (PDA) than traditional mobile phones. Of course the calling function is still on these machines. PDA's are coming to the wireless markets. Firstly by help, later on by autonomously. Laptops already are members of wireless markets, thanks to data line. On future the laptop will be more powerful tools on wireless content market. Especially when the data transaction capability enlarges. Perhaps on future we will get more wireless orientated services for laptops. As summa samarium we may accord the expectation of Moore's ${ }^{9}$ law to come on the mobile phone markets.

Electrical charging channels on Internet has been problematic. Internet market members have tried to create electric money, but unfortunately without success. Many flops has came; DigiCash went to bankrupt, CyberCash dropped its product and First Virtual Holdings (present MessageMedia) transferred into another business area. Reasons for unsuccessful business were on narrow business area and on complicated use structure. On the first generations e-cash systems the consumers have to 
install specific software before they were able to use electric money. The money was usable only on those places that had installed that similar software. ${ }^{2,10}$ On present there is a lot of ideas and development on this area. IBM is making one system, Visa electron has one and Mondex has arrived on intelligent card area. Interested is to see whether these new forms include also wireless network. Keystone for all of these systems, including also this paper, is the reach of critical mass. Without critical mass reach will every new systems disappear from the markets! Creators should always remember the customer on these payments. Too complicated and separated systems are not desirable. No one is willing to study many security numbers and pin codes. At the same time we have to remember that too centralised system will enlarge the bill on the risk level. Too high bill will influence on the usage. Well, there should also be potential. More networks to cover up the more contacts to customer will be. Payment systems for this networked world might be quite complicated.

\section{MICRO-PAYMENT SYSTEM}

Micro-payment system is objected on small payments, less than 1 Euro. Normal charging channels are usually too expensive to be used. Transaction costs may arise on a higher level than the payment itself. There are many small services on markets to where should- and could- be charged something. Markets need a new channel to take care these small payments. This new channel may open totally new areas for service providers to make business and to easier the customer's daily living. Bridge/head toll, coffee automatics and all those places where coins are needed may be deal with more easily.

The development process for our micro-payment idea started from these above-mentioned facts. We were looking for a payment system that can be located on every wireless channel without dependence of used network. New systems ideation let freedom for creators. We form the freedom on three main values. Values were anonymity of money; payment base on the usage and independence of used network. Solution brought out from the service identification base. If we are able to identify the service, it will let other values to existing.

\subsection{Basic idea}

'Create financial tool for micro- payments by service identification' 
Basic idea requires three main functions to be created on markets and on equipment. On Figure 2 these functions are drawn.

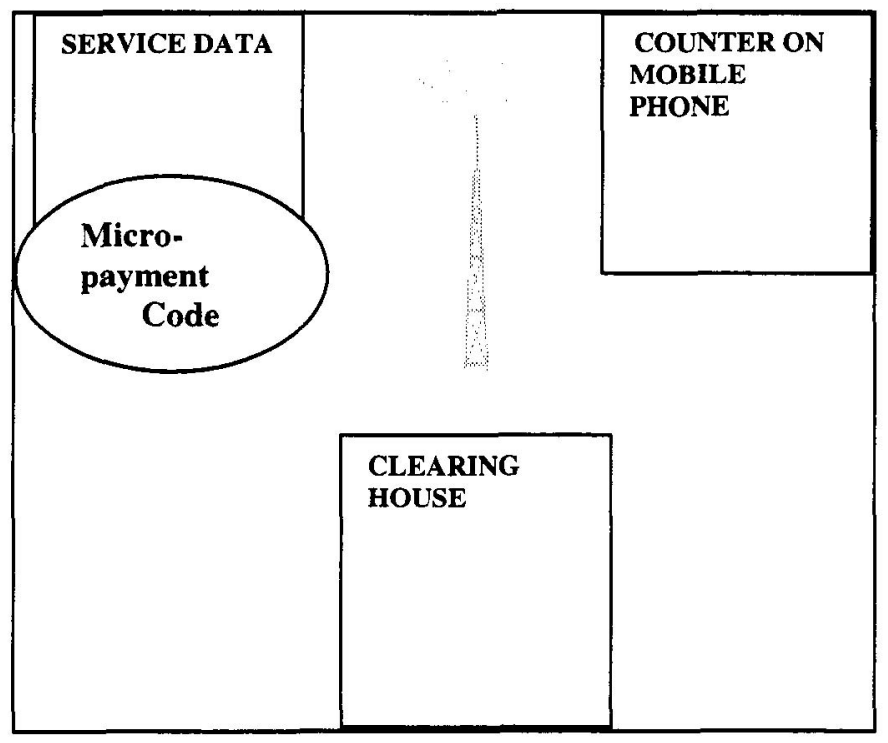

Figure 2. Basic structure of micro-payment

Basic idea is to add micro-payment code on the service software and name the transferred money by the mark of service ${ }^{14}$. Micro-payment code will be added as a form of tickets. On mobile phone side there will be a counter inside the phone. The counter picks up the tickets from the service broadcast. Tickets on the counter are service named. Later on transferred money is service named.

\subsection{Functionality of micro-payment system}

Service providers create the content for service. When the content is released on distribution channels will it include identification ticket and time depend consume tickets. Tickets are tied inside the transferred information. First ticket identifies the service. Following ones measures the consumption of service. Every time when new ticket arrives will the counter pick it up. Counter collect these tickets some settled time and after that sends the information to service provider, bank or clearinghouse. Send information is a composed of service identify ticket and consume tickets. Provider may change these tickets in the physical money on banks. Clearinghouse can also 
share incoming money for right service providers. In Figure 3 one has drawn basic functionality for system.

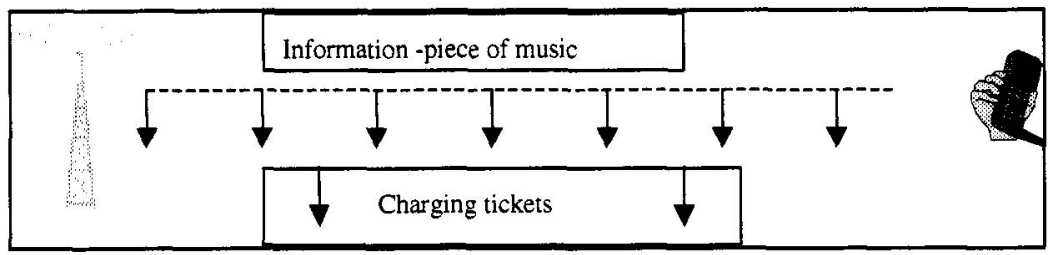

Figure 3. Service data transfer and tickets

Tickets are the bases of charging. First ticket includes service's identification information. This ticket names the service for bank and define income sharing. Roxette's piece of music, parking fee, and weather information etc get their own code. Second and further tickets are only measurers of service consumption. Counter on the consumer's mobile phone collects these tickets. Counter has to be created on the trusted part of phone. Reasonable place for counter could be SIM- card, which at this moment is the trusted place of mobile phone ${ }^{8}$. The charge is depended on the numbers of receipt tickets so on the payment is tied on the real usage base. For example, if customer is able to listen music only 2 minutes and 10 seconds, unless the play is 3 minutes 20 seconds long, will he receive tickets only for the listening time and pay on this consumption, but not more. On Figure 4 there has been drawn this situation together with service providers money realisation.

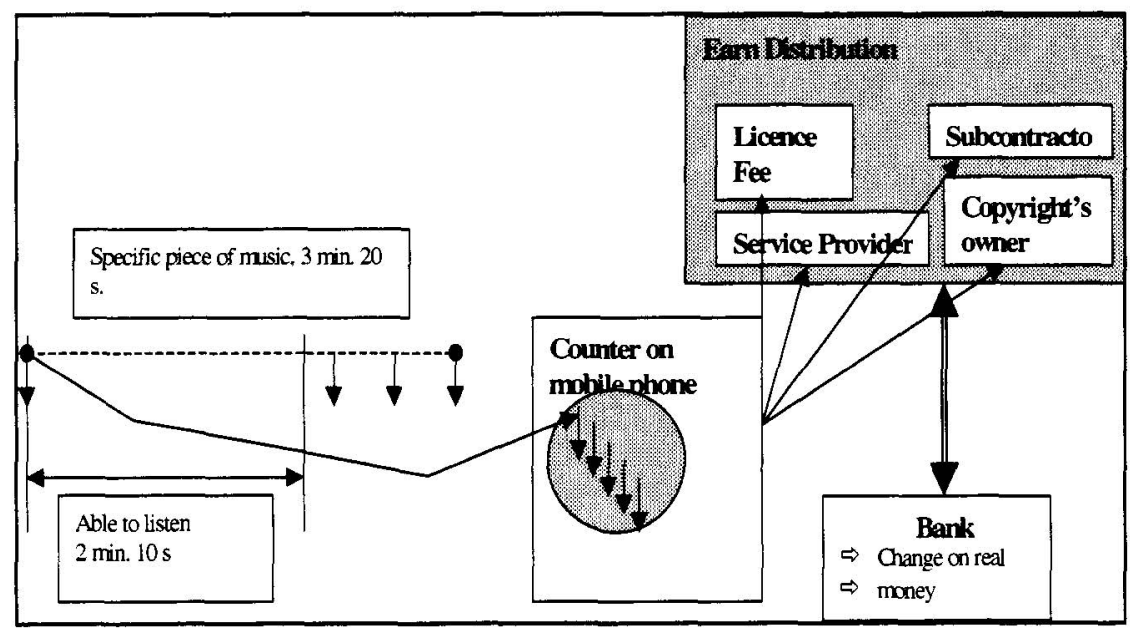

Figure 4. Functionality of micro-payment 
Customer opens the service and music starts. Before the start will identification ticket arrive with the necessary information of charging. In every 26 seconds there is smaller consume- ticket that measures consumption. On this case the consumer is able to listen 2 minutes 10 seconds so on there will arrive 5 tickets to the counter. When the customer close the service will it also close the counter. In the end of agreed period will the mobile phone contact to clearing house, service provider's server or bank and send the tickets there. Clearing house, service provider or bank take care of service named tickets change on the real money and the money distribution on the value chain. When is need can clearinghouse collect all tickets from mobile phone counters. Capability to avoid encroachments is a necessity in all of this kind of systems.

Counter is the consumer tool in this system. Counter is a pit like a mobile phone wallet that includes 'real' money. Money can be loaded before use or user may made a deal with bank that $\mathrm{s} /$ he have some specific number of money to use. Counter doesn't include consumer's identification, it only picks up identified codes from services and save them for certain period. When customer pick up a service ticket will the balance of payments change. Used money will be saved on counter and be named by the service. There is no possibility to double use this money. Money is a faceless measurer in this system and there is no need to create identification around consumer. Service itself is identified so on the customer pays service-identified money for third party. Functionality is quite easy. When customer start to enjoy the service will $\mathrm{s} / \mathrm{he}$ first receive the service identification ticket and later on regularly the consume tickets. Together with service identification ticket there arrives information of service's pricing. Counter pick up identification ticket and consuming tickets. Later on these tickets will be sending to the clearinghouse, bank or service provider's server. Send money is named by service and is changeable in banks. The trustfulness of money transactions will be made by service identification. If the external participant get transferred money it is unusable for him. The money change in bank will transfer it for right service provider account.

Counter gives information for customer about the balance of money and from customer's buying behaviour. Functionality is quite similar like in a normal wallet. On wallet there is usually money- not much, but enough. More money can always draw out from an account. If the money is end and counter is empty, then the services will be out of reach. Consuming behaviour is always on customer's awareness. Balance of account and 
information of recent consume has to be saved on system. In Figure 5 are drawn one possible consume with this system.

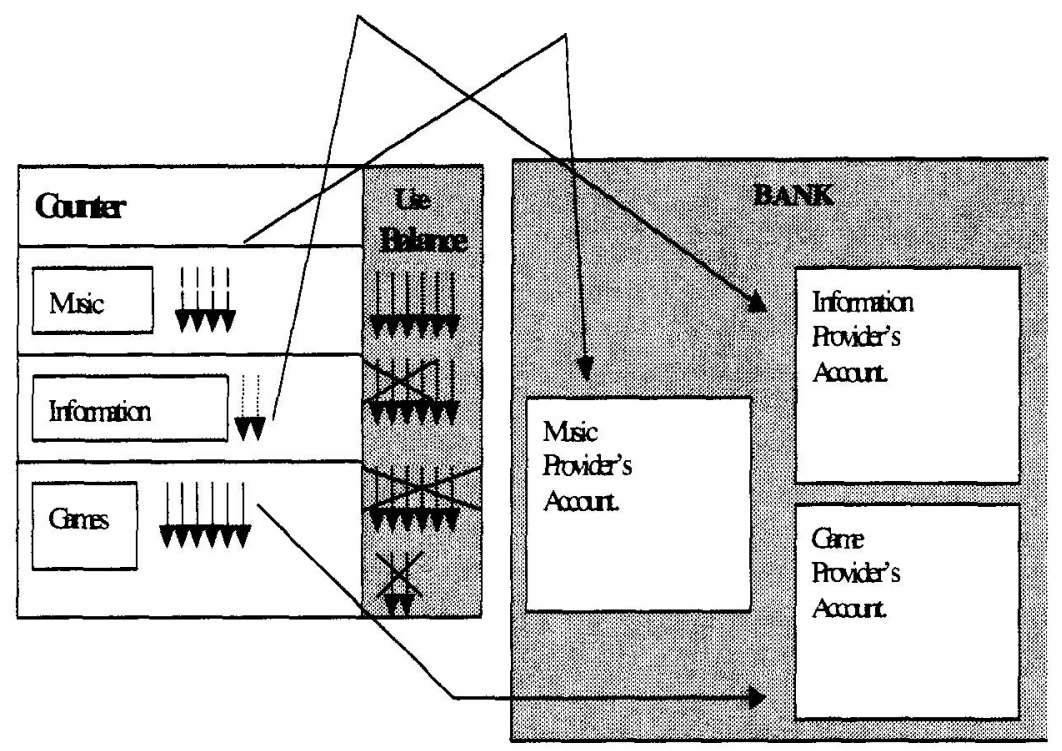

Figure 5. Counter and income distribution

\subsection{Identification- and consuming tickets}

Service identification is on major role in this kind of system. Each service has to be identified so clearly that trustworthiness for money transaction can be guaranteed. The number of services is strongly increasing, which requires large space for identification tickets. Tickets during the broadcast have to own enough identification information that consuming can be measured. Wireless world is also unstable so on the broadcast can include short times without connection, unless consumption continues. This brought up the need for the recognition between service identification ticket and consumes tickets. After consumption there will be send only one financial ticket for clearinghouse, bank or service provider. All these tickets have to be unrecognisable on the broadcast. Even the consuming ticket may not force notable blackout during the broadcast of service. Service itself owns the major part of transferred information and financial information just has fused in the content information.

Identification ticket is the hard of system. Ticket's main function is to possibility the service's trusty identification and money naming for certain service. The size of the identification ticket is allowed to be a pit larger than 
consumption tickets, because of its early location in broadcast. Consuming ticket should be quite light. On Figure 6 has drawn educated identification ticket on the broadcast.

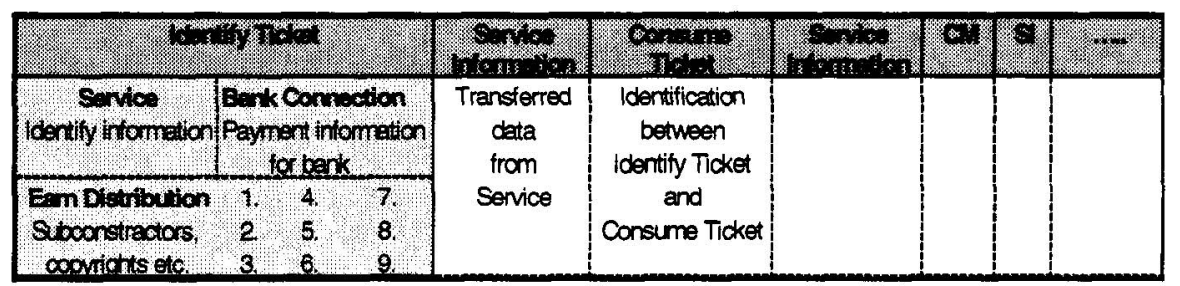

Figure 6. Identification and consumption tickets during the broadcast

Educated identification ticket includes trusty service identification, information of the bank connections and direct income distribution. Direct income distribution comprehends the value chain of the service. For example on music it will mean direct payment for composer, lyrics, performer and for record producer and all these almost on real time.

Consume measurement ticket is a short piece of code wherewith identifies the measurement of service consuming. (Figure 6). Continuous service, that is enjoyed by customer, is a composed of service's data and charging data. When a customer has a possibility to enjoy service for certain time -not the whole service, but some part of it, there is a need to measure the number of enjoyed service. Consume measurement ticket take care on this measurement. Consuming tickets are hides inside the transferred information. Consume ticket recognise the identification ticket being an agent for it. Main functionality is to measure the number of use in continuous consuming.

Sometimes there is a need to identify customer before service may begin. Closed networks for certain group or services that are intended only for adults may require a 'key' before begin. Some services should be enjoyable only for members. Many hotels, banks and insurance companies offer bonus services for customers to, which opens the need to identify the customers. Our value were anonymous money so on the solution requires independent customer identify ticket. This ticket identifies the customer when it is necessary, but it hasn't any connection on the money spending. It is more like an opener or a key for the service. When the service requires identification will this ticket be send to customer and for which $\mathrm{s} / \mathrm{he}$ has to answer. The answer opens the service. 


\section{THE EFFECTS AND THE ADVANTAGES FOR THE MARKETS}

Mobile content markets require flexibility. As we all have notice the success on Japan, made by i-mode, have been huge. There have many answers for the success. One could be the openness of the content development. Customers and providers are able to create own sides, services and information for the markets. Maintenance, in this connection NTT DoCoMo, can choose and authorised the best services as in the form of official sides. On that case the service development possess Tapscott's et al (1999) introduced virtual factory attributes. Valuable for markets is the service's success basement that has build on the real value of the service. Most valuable services will be chosen on the position of the official side. Second reason for Japanese success on mobile market may come from the earnings principles. NTT DoCoMo's part from the service's incoming money is smaller than on Europe. Has this influence on the wealth of services provider or not -we don't know. Of course there is many cultural, economical and other reasons between Europe and Japan, but we should look carefully for to identify the right tasks on our development here in Europe.

Flexibility, to look after, could come from payments. If the market's can offer independent payment process for service provider, will the barrier of entry on content market decrease. On that case the operator's role is to be a connection enabler. Operators still have a position to be the master of choosier in the service area, if they are able to keep their good brands and roles on market. Capability to offer official service is strong force on markets. Essential is the change for everybody to try to reach the success by own service. Easy entry on the markets will rise the competition between content providers as the theory of perfect competition has shown to us.

Networks technical convergence will require new methods. On near future there will be many networks and standards on the wireless markets. It is not reasonable to solve payment problem on each of these. We need something to encourage this convergence development. Common payment model for every network could be one encourages.

Micro-payment readiness for customers might increase the usability and the usefulness of mobile life style. Coins require services might be enjoyable without the need of material coin. Services may be paid immediately. There is no need to cumulate payments for one month. Payments could be objected 
more clearly on the real consumption places. On negative side there will come new numbers to learn

System is not depended on the information distribution channels. On future the wireless and networked world will increase to contain many operative levels and channels for service distribution. Levels begin on very near and local continuing until global level. People's personal level includes technical equipment nearby individual, such as home equipment. Local area networks, such as city depended portals, W-lans, local providers etc offers services for certain place. WAN (wider area network) creates network around the country or with alliances around the world. (Figure 6). Internet and mobile network are examples of globally networks. Services in different distribution channels might be identical. Charging in many channels may become complicated. One charge system used in country level, second on personal and third on city-portals generates may become too complicated charging system for customers. When service has identification and consumption tickets can charge be based on similar type in each of these channels. ${ }^{13}$

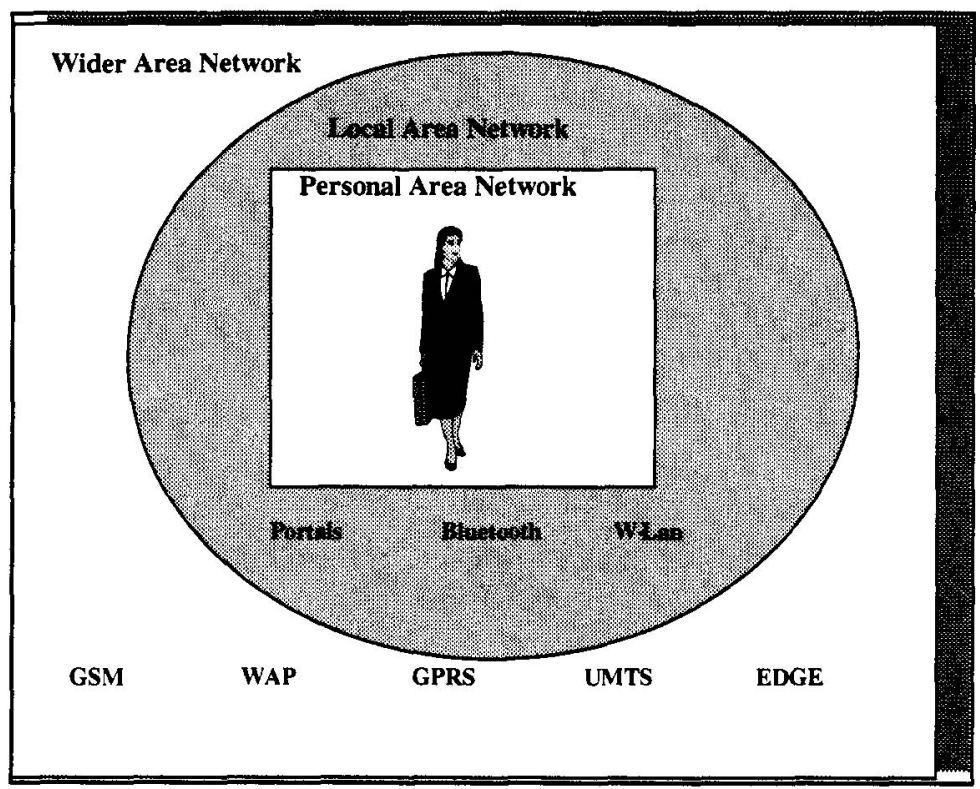

Figure 7. Networks around customer

System can be linked on existing customer network. Shops, banks, operator's etc have created quite large customer networks around them. 
Networks loyal customers should enjoy different services somehow better than the outsiders should. Customer satisfaction is a key force on these customer networks. Micro-payment system can be one tool to compete on this competition.

Existing micro-payment system may offer powerful tool for advertisement. System can be ordered to operate reversed. Someone else load your counter, if you are willing to do something for him. This something may be readied advertisement. Advantages for both sides are strong. Advertiser can be sure that commercial information has reached customers. Customer will earn some money by reading that commercial information. Of course if customer is not interested to have that information $\mathrm{s} /$ he may just forget it and so on $\mathrm{s} /$ he will not earn anything from that advertisement.

\section{FUTURE PLANS}

Operative micro-payment system requires technically quite much. Our aim at present is to create technical testing platform for this system. Implementation environment will be mobile phone with traditional card game. Target is quite good. Game requires online connection, real time information from movements and wins/losses. Game time for one session might be endless (fully continuous game) and even in the best case the game will take few shares before end. Game's functional space requires enough for us to test and create system so far that it can be assign on other services. Technical testing task will arrive on the usability of micro-payment system and on data transactions. Research question in that case is to create system so that it will not bother the host service's usability.

\section{ACKNOWLEGEMENTS}

This research has been conducted in research project Monica (Development of Production Facilities of the Value-Added Mobile Services in Distributed Environments ) funded by TEKES, Nokia Mobile Phones, Sonera, Solid, Elektrobit, CCC, Necsom, VTT Electronics and University of Oulu. 


\section{REFERENCES}

[1] Http://Monica.oulu.fi

[2] Anonumouys (2000): E-cash 2.0, Economist 02/19/2000, Vol. 354, London, 3 pages

[3] Hoch, D; Roeding, C; Purkert, G; Linder, S; Muller, R (1999): Secrets of Softaware Success, Harvard Business School Press, Boston

[4] IST (2000): The Book of Visions 2000 -Visions of the wireless world, Version 1.0, EU/ IST programme.

[5] Ministry of Transport and Communications Finland (1999): Suomen tekstiviestimarkkinat, Publications of the Ministry of Transport and Communications Finland, 47/99, Helsinki

[6] Shapiro,C; Varian, H (1999): Information Rules, Harvard Business School Press, Boston

[7] Tapscott, D; Ticoll,D; Lowy,A (2000): Digital Capital, Harvard Business School Press, Boston

[8] Upton, D.M.; McAfee, A (1996): The Real Virtual Factory, in the book of Creating Value in the Network Economy, Harvard Business review book series, Boston 1999

[9] Moore, G,A (1995): Inside the Tornado, Harper Press, New York

[10] Wodinski,J; Zafar, S (1999): E-cash, American Banker 09/10/99, Vol 164, 3 pages

[11] www.NTTdocomo.com

[12] www.Sonera.com

[13] www.durlacher.com: UMTS report, 25.3.2001.

[14] Karvonen, J; Pulli, P (2001): Wireless Micropayment Systems, Proceedings of the WWRF Kick-off Meeting, Munich, Germany, 2001 